\title{
Alterations in Human Fetal Hematopoiesis Are Associated with Maternall HIV Infection
}

\author{
Y. BURSTEIN,' W. K. RASHBAUM, W. C. HATCH, T. CALVELli, M. GOLODNER, R. SOEIRO, \\ AND W. D. LYMAN \\ Departments of Pathology, Obstetrics and Gynecology, Pediatrics, and Medicine, Albert Einstein College of \\ Medicine, Bronx, New York 10461
}

\begin{abstract}
In the majority of adult and pediatric patients with AIDS, hematologic abnormalities including leukopenia, anemia, and thrombocytopenia are commonly observed. In addition to these findings, changes in hematopoietic progenitor cells occur, including a reduction of multipotential-forming units, granulocyte-macrophages, macrophage as well as eosinophil colony-forming units, and bone marrow erythyroid burst-forming units. This study examined alterations in human fetal liver hematopoiesis in 2nd trimester abortuses from human immunodeficiency virus (HIV)-seropositive women. The differentiation and growth potential of hematopoietic cells in vitro were monitored. Upon initial isolation, some populations of liver hematopoietic cells from abortuses of HIV-seropositive women were significantly decreased when compared to age-matched samples from fetuses of normal females including the percentage of early $T$ cells [cluster of differentiation (CD)2], B cells (CD19), and early monocytes (CD14). A decrease in multipotent progenitors (CD34), myelomonocytes (CD33), and panleukocytes (CD45) was also observed. In contrast, after $21 \mathrm{~d}$ in culture, cells from HIV abortuses demonstrated an increase in the percentage of CD14 cells when stimulated with erythropoietin and granulocyte-monocyte colony-stimulating factor, as well as an increase in CD45 phenotype after exposure to granulocyte-monocyte colony-stimulating factor alone. These samples showed a persistence of erythropoietic elements (transferrin and CD36 phenotype) when compared to normal controls. No significant difference in the in vitro growth of hematopoietic progenitors (bone marrow erythroid burst-forming units, granulocyte-macrophage colony-forming units, and multipotential forming units) between these samples and normal controls was found. These findings may be the result of transplacental hematopoietic inhibitors produced as a consequence of maternal HIV infection that result in similar hematologic abnormalities in AIDS patients. (Pediatr Res 32: 155-159, 1992)
\end{abstract}

\section{Abbreviations}

BFU-E, bone marrow erythroid burst-forming unit $\mathrm{CD}$, cluster of differentiation

CFU-GEMM, multipotential-forming unit

CFU-GM, granulocyte-macrophage colony-forming unit

CFU-MK, megakaryocyte colony-forming unit

Ep, erythropoietin

GM-CSF, granulocyte-monocyte colony-stimulating factor

Received December 11, 1991; accepted March 6, 1991.

Correspondence: Dr. William D. Lyman, Department of Pathology, Rm. F-514,

Albert Einstein College of Medicine, 1300 Morris Park Ave., Bronx, NY 10461.

Supported by United States Public Health Service Grants DA 05583, MH 46815, and $\mathrm{MH} 47667$ and the ATRAN Fund.

'Present address: Head, Pediatric Hematol/Oncol Unit, DANA Children's Hospital, Ichilov Hospital, 6 Weizman Street, Tel Aviv, Israel 64239.
HIV, human immunodeficiency virus

HIV-1, human immunodeficiency virus-type 1

PE, phycoerythrin

PCR, polymerase chain reaction

rhGM-CSF, recombinant human granulocyte-macrophage colony-stimulating factor

FL, fluorescence

AIDS is the result of infection of susceptible cells by HIV-1 (1, 2). Although the tropism of HIV-1 for CD4+ lymphocytes and monocytes appears to be central in the pathogenesis of disease (3), abnormalities in hematopoiesis with resultant peripheral blood cytopenias also occur $(4,5)$. Granulocytopenia has been reported in most patients with AIDS or AIDS-related complex (6). An even higher incidence of anemia has been noted in a series of individuals with AIDS (7). Similar abnormalities are observed in HIV-infected infants and in others who show only transient HIV seropositivity due to transplacentally acquired anti-HIV antibody (8).

The bone marrow and hematopoietic progenitor cell compartments are defective in HIV-1 patients $(9,10)$. Dysregulation of hematopoiesis by alteration in the $\mathrm{T}$ cell subpopulations (11), production of inhibiting glycoproteins (12), antibody-mediated cytotoxicity (13), and infection of hematopoietic progenitor cells by HIV-1 (14) have all been implicated as pathogenetic mechanisms. Bone marrow specimens taken from patients with AIDS exhibit myelodysplastic changes (15). A reduced proliferative capacity in vitro of CFU-GM from the bone marrow of 16 out of 18 patients with AIDS and concurrent neutropenia has been described. Significant reduction of CFU-GEMM, BFU-E, and CFU-MK has also been observed (11).

Maternofetal transmission of HIV-1 resulting in children with AIDS is emerging as a major manifestation of this disease. There is a high risk (about 30\%) of HIV-1 infection in children born to seropositive mothers $(16,17)$. Because the majority of children with AIDS are congenitally infected by HIV-1, hematopoietic organs other than the bone marrow may have a direct relationship with the hematologic abnormalities associated with pediatric AIDS. Because the liver represents the major organ of extramedullary hematopoiesis during fetal life and HIV-infected children are believed to be infected in utero (18), some of the hematologic manifestations related to pediatric AIDS may be the product of infection of hematopoietic stem cells in the human fetal liver. To investigate these possibilities, fetal liver hematopoiesis in abortuses of women infected by HIV was studied in vitro and compared to that in normal control fetuses.

\section{MATERIALS AND METHODS}

Source of fetal tissue. The present study is part of an ongoing research protocol that has been approved by the Albert Einstein 
College of Medicine Committee on Clinical Investigation and the Health and Hospital Corporation of the City of New York. Informed consent was obtained from the participants. Fetal tissues were obtained at the time of elective pregnancy termination from normal and from HIV-seropositive women. The gestational ages of the abortuses ranged from 15 to 18 wk. Each sample was compared with age-matched controls in the following analysis.

Maternal and fetal blood studies. Five HIV-seropositive and eight normal control 2nd trimester pregnant women were studied. Routine blood studies included complete blood count [using the Coulter S plus IV (Hialeah, FL)], total lymphocyte count, T4 and $\mathrm{T} 8$ subsets, and coagulation profile. Sera from all patients were tested for antibodies to HIV using the ELISA and Western blot techniques. Fetal cord blood and amniotic fluid were analyzed for anti-HIV antibodies by ELISA and Western blot techniques.

Analysis of HIV-1 infection of fetal tissues. The potential of HIV-1 infection of fetal liver and other tissues was determined by autoradiography after PCR of potential HIV-1 DNA sequences.

Abortuses were obtained after dilation and extraction. Within 10 min of fetal demise, the external surface of the abortus was thoroughly rinsed with saline and the fetus surgically dissected to yield tissue samples including, but not restricted to, CNS, liver, and lung. The tissues were snap frozen in liquid nitrogen and maintained at $-70^{\circ} \mathrm{C}$ until analyzed. For DNA analysis, tissues were thawed on ice and mechanically dissociated into cell suspensions by passage through a sterile stainless steel mesh screen, cells were washed by sedimentation through PBS, and nucleic acids were deproteinized by standard phenol, chloroformisoamyl alcohol purification.

One $\mu \mathrm{g}$ of tissue DNA was amplified for 30 cycles using the "gag" oligonucleotide primers SK38 and 39, the thermostable "tac" polymerase, and the salt and Mg optimization as described by the manufacturer (Cetus, San Francisco, CA). Detection of HIV-1 DNA was accomplished using the radiolabeled SK19 probe. In each case, a negative control DNA was obtained from a blood donor who was without risk factors for HIV-1 infection and who had been determined to be seronegative. Positive control DNA was composed of $1 \mu \mathrm{g}$ of HIV-1-negative DNA to which had been added measured quantities of HIV-1 plasmid DNA genome copies or measured quantities of whole cell DNA from the 8E5-LAV cell. This cell line is known to contain a single proviral copy of HIV-1. All amplifications included both negative and positive controls and were done at least in duplicate.

Tissue culture. Fetal livers were obtained within $10 \mathrm{~min}$ of delivery. The organs were placed in Hanks' balanced salt solution containing $0.1 \%$ heparin. The livers were dissected sterilely and cells collected into 50-mL centrifuge tubes, and tissue debris and aggregates were allowed to settle by gravity. A mononuclear cell preparation was prepared by centrifugation over Ficoll Hypaque. The cells at the interface were washed twice in Hanks' balanced salt solution and the number of viable cells determined using trypan blue.

Cell cultures. In each experiment, HIV-positive and control cells were simultaneously cultured using the same conditions. RPMI-1640 (GIBCO Laboratories, St. Lawrence, MA) supplemented with $10 \%$ FCS (GIBCO), 100 units of penicillin, $5 \mathrm{mg}$ streptomycin, and $0.9 \%$ methyl cellulose was used (wt/vol). Part of each sample was cultured in liquid suspension without addition of methylcellulose. The cells were resuspended in the medium and adjusted to $5 \times 10^{5}$ cells $/ \mathrm{mL}$. One $\mathrm{mL}$ of cell suspension was cultured in either 24-well or 6-well tissue culture plates. Cells were cultured in the presence of $1 \mathrm{IU} / \mathrm{mL}$ Ep (purified human urine ICN Biochemicals, Cleveland, $\mathrm{OH}$ ) and rhGMCSF (Genzyme, Boston, MA) at $5 \mathrm{IU} / \mathrm{mL}$. In some wells, only Ep or GM-CSF was added to the cell suspension.

After 5,10 , and $21 \mathrm{~d}$ of incubation at $37^{\circ} \mathrm{C}$ and $5 \% \mathrm{CO}_{2}$ in a moist atmosphere, cell colonies were examined, classified, and counted in the 6-well plates using an inverted microscope. Red colonies usually containing more than 1000 cells were scored as BFU-E; although after $5 \mathrm{~d}$ in culture some investigators would call them erythroid colony-forming units, we use BFU-E to maintain internal consistency. Colonies containing nonhemoglobinized cells (primarily granulocytic precursors and macrophages) were scored as CFU-GM, whereas colonies containing both erythroid cells and one or more classes of phagocytic or megakaryocytic cells were scored as CFU-GEMM. Colony-forming units-megakaryocyte were defined by the relative size of the cells. Colonies are expressed as number of colonies per $10^{5}$ cells.

Flow cytometry. The reagents used for immunofluorescent staining and flow cytometric analysis are shown in Table 1.

Phenotypic analysis of isolated fetal cells was carried out by direct and indirect staining with MAb. Briefly, cells were washed three times with PBS containing $2 \%$ FCS, and all samples were incubated on ice with purified human IgG for 30 min to block Fc receptors. Direct, dual-color staining was carried out by incubation with the following FITC and PE-conjugated MAb on ice for 30 min: HLe1FITC/Leu-M3-PE. [anti-CD45/CD14: Leukogate, Becton-Dickinson, Los Angeles, CA (Simultest), BectonDickinson, San Jose, CA)]; Leu-2a-FITC/Leu-4-PE (anti-CD8/ CD3); Leu-3a+3b-FITC/Leu-16-PE (anti-CD4/CD20); and T4FITC/4B4-RD1 (anti-CD4/CD29). Indirect staining was carried out by incubation on ice for 30 min with Leu-20 (anti-CD23), Leu-M9 (anti-CD33), My10 (anti-CD34), IOP36 (anti-CD36), or IOP61 (anti-CD61) at predetermined optimal concentrations. Cells were washed three times with PBS containing $2 \%$ FCS and $1 \% \mathrm{NaN}_{3}$ and incubated with goat anti-mouse IgG conjugated with FITC (GAM-FITC, Becton-Dickinson, Los Angeles, CA). After three additional washes, both directly and indirectly stained samples were fixed overnight in $1 \%$ paraformaldehyde at $4^{\circ} \mathrm{C}$, washed, and resuspended in PBS for flow analysis. For direct immunofluorescent staining, FITC- and PE-conjugated mouse

Table 1. Panel of antibodies used for phenotypic analysis $\mathrm{CD}$

\begin{tabular}{cccc} 
Antigen & designation & Normal cellular expression & Source* \\
\hline Leu-1 & CD5 & $\begin{array}{c}\text { Thymocytes; activated T cells; subset } \\
\text { of normal B cells }\end{array}$ & BD
\end{tabular}

Leu-3a,b CD4 Normal thymocytes; T helper/inducer cells; monocyte/macrophages

Leu-4 CD3 Thomocytes; mature, mitogenic T cells

Leu-2a CD8 Suppressor/cytotoxic T lymphocytes; NK cells

Leu-1b CD20 Mature cells

Leu-20 CD23 B cell differentiation antigen activated monocytes (low affinity IgE Fc receptor)

4B4 CD29 Helper-inducer CD4 and T cell; subset expressed on hematopoietic cells, $T$ cells, and monocytes

B4 CD19 Early and mature B cells (expressed before $\mathrm{CD} 20$ )

T11 CD2 All T cells (E rosette receptor)

Leu-M3 CD14 Monocyte/macrophage antigen

HLE 1 CD45 Panleukocyte antigen

Leu-M9 CD33 Human myelomonocytic antigen; promyelocytes and metamyelocytes

My10 CD34 Uni- and multipotent progenitor BD cells

IOP36 CD36 Very early erythroid differentiation BD antigen

IOP61 CD61 Platelet glycoprotein, GP IIIa; plate- A let and megakaryocytes

* BD, Becton Dickinson; C, Coulter; and A, Amac (San Jose, CA). 
$\mathrm{IgG}$ isotypic controls were processed for each sample. For indirect staining, a GAM-FITC control was processed for each sample.

Cells were analyzed using a FACScan flow cytometer (Becton Dickinson Immunocytometry Systems, San Jose, CA). All results were based on acquisition of 10000 cells per sample using Consort 30 software and analysis with Consort 30 and LYSYS software (Becton-Dickinson, Los Angeles, CA). The percentage of positive cells for each MAb was determined by single (FL1) or dual $(\mathrm{FL} 1 \times \mathrm{FL} 2)$ parameter list-mode analysis of events gated to exclude debris on a forward $\times$ side scattergram.

Statistical analysis. The results were analyzed using the "Statistics" program (version 5.1), produced by Basic Business Software, Inc. (New York, NY). The colony counts were analyzed by the $t$ test and the flow cytometric data by the $t$ test after conversion by two-way analysis of variance.

\section{RESULTS}

Maternal blood studies. Maternal blood studies including $\mathrm{Hb}$, total white cell count, total lymphocytes, T4:T8 ratio, platelet count, and mean platelet volume are shown in Table 2 . Of the five HIV-seropositive females, one woman suffered from a microcytic hypochromic anemia and another had leukopenia. All women had abnormal T4:T8 ratios. Two women presented with thrombocytopenia; both showed an increase in mean platelet volume that probably is due to an immune process. There were no abnormal values in the blood samples for the control females.

Potential HIV-1 infection of fetal tissue. There was no evidence by PCR to support the conclusion that any of the fetal tissues examined as part of this study were infected by HIV.

Fetal liver hematopoietic cultures. Table 3 demonstrates colony formation of fetal liver hematopoietic cells from abortuses of normal and HIV-seropositive females. Cultures were stimulated with Ep+ GM-CSF or GM-CSF alone and counted on d 5 and 10. Although fetuses of HIV-seropositive women showed a normal number and size of colonies of GFU-GEMM and CFU$\mathrm{GM}$, there was a significant $(p<0.01)$ difference between the normal and HIV samples with respect to colony-forming unitsmegakaryocyte on d 5. However, by d 10 there were no differences between the cultures.

Flow cytometric analysis. The relative percentages of lymphoid and nonlymphoid lineage MAb-positive fetal hematopoietic cells before culture are shown in Table 4 , in which normal tissue is compared with tissue derived from abortuses of HIV-seropositive women. Normal cultures contained $6 \%$ of CD-19-positive cells (early B cell antigen) and 4\% of cells expressed CD2 (an early T cell marker). Fetal liver hematopoietic cells from abortuses of HIV-seropositive women demonstrated a significantly lower number $(p<0.01)$ of CD19- and CD2-positive cells ( 2 and $1 \%$, respectively), as well as fewer cells with CD14 phenotype $(p<$ 0.02).

A nonsignificant decrease in multipotent progenitors (CD34) and myelomonocytic (CD33) and panleukocyte (CD45) antigens was also demonstrated. No difference was observed in the erythroid lineage (transferrin and CD36) either.

The relative percentages of erythroid and monomyelocytic phenotypes of cultured hematopoietic cells stimulated with Ep+GM-CSF or GM-CSF on $d 10$ and 21 are shown in Tables 5 and 6 , respectively. There is a significant increase $(p<0.02)$ in the number of CD14-positive cells in the fetal cultures for HIV-positive females on d 21 when stimulated with Ep+rhGMCSF. The same samples showed a significant increase $(p<0.01)$ in the number of CD33-positive cells in cultures of HIV fetuses stimulated with Ep+rhGM-CSF on d 21 compared to normal controls. Transferrin- and CD36-positive cells, which are markers for the erythropoietic compartment, showed a $40 \%$ reduction between d 10 and d 21 ( 84 to $51 \%$ and 73 to $49 \%$, respectively), whereas no changes were observed in transferrin- and CD36positive cells originating from HIV fetuses ( 71 to $68 \%$ and 68 to $62 \%$, respectively). No significant changes were observed in the megakaryocytic lineage (CD61).

\section{DISCUSSION}

The results of the present in vitro analysis of fetal liver cells from abortuses of HIV-seropositive women demonstrated significant changes in the phenotypes of some cells and hematopoietic progenitors when compared with normal control values. These changes were similar to those observed in bone marrow specimens of patients with $\operatorname{AIDS}(9,10)$.

The major difference noted in this study was in the early $T$ and B lineages, which showed a significant decrease in the percentages of cells originating from the liver of fetuses of HIVseropositive women. One can speculate that the deficiency of immature lymphoid elements could be related to a maternal suppressor factor or factors secreted by $\mathrm{T}$ cell subpopulations. This may be the same mechanism that is responsible for lymphopenia observed in peripheral blood of patients with AIDS Leiderman et al. (19) were the first to describe a reduced in vitro proliferative capacity of CFU-GM from the bone marrow of 16 out of 18 patients with AIDS and concurrent neutropenia. It was concluded that bone marrow cells from patients with AIDS released a factor inhibitory for normal granulopoietic progenitor cells. It was further reported (20) that bone marrow progenitors isolated from AIDS patients are responsive to rhGM-CSF and recombinant Ep and that antibodies present in the serum of patients infected with HIV could suppress the growth of these progenitors. A component of this immune-mediated suppression appears to be antibodies directed toward the envelope glycoprotein $(g p 120)$ of HIV-1.

A decrease in CFU-GEMM, CFU-MK, BFU-E, and CFU-GM from bone marrow of patients with AIDS was found to be inversely correlated with the number of circulating CD4 cells and the T4:T8 ratio (21). This observation leads to the conclusion that an imbalance of $T$ cell subpopulations appears to be mainly responsible for the progressive impairment of proliferation and differentiation of bone marrow progenitor cells observed in HIVinfected individuals. The present report demonstrates a decrease in myelomonocytes (CD33), panleukocytes (CD45), and early monocytes (CD14), but we failed to demonstrate any suppression of BFU-E, CFU-GM, CFU-GEMM, and CFU-MK. There was some evidence that those hematopoietic cells are more responsive

Table 2. Hematologic profile of HIV-seropositive women

\begin{tabular}{|c|c|c|c|c|c|c|c|}
\hline & $\mathrm{Hb}^{*}$ & $\mathrm{WBC} \uparrow$ & $\begin{array}{c}\text { Total } \\
\text { lymphocytes }\end{array}$ & $\begin{array}{c}\text { Total } \\
\text { T4:T8 }\end{array}$ & $\begin{array}{l}\text { Ratio } \\
\text { T4:T8 }\end{array}$ & Platelets & MPV§ \\
\hline 1 & 11.8 & 3.3 & 924 & $92 / 675$ & 0.14 & 131 & 11.0 \\
\hline 2 & 11.8 & 7.6 & 1748 & $350 / 1013$ & 0.34 & 272 & 7.9 \\
\hline 3. & 9.4 & 6.4 & 1088 & $239 / 631$ & 0.38 & 274 & 7.8 \\
\hline 4. & 13.7 & 4.9 & 1786 & $319 / 1386$ & 0.23 & 88 & 12.2 \\
\hline 5. & 11.0 & 7.4 & 1874 & $687 / 850$ & 0.73 & 157 & 10.4 \\
\hline
\end{tabular}

$* \mathrm{~g} / \mathrm{dL}$

$\dagger$ WBC, total per $\mu \mathrm{L} \times 10^{3}$

$\ddagger$ Total per $\mu \mathrm{L} \times 10^{3}$.

$\S \mathrm{MPV}$, mean platelet volume in $\mathrm{fL}$. 
Table 3. Hematopoietic cell colonies after addition of growth factors to cultures (no. of colonies $\pm S E M / 5 \times 10^{5}$ cells)*

\begin{tabular}{|c|c|c|c|c|c|c|c|c|}
\hline & \multicolumn{2}{|c|}{ BFU-E } & \multicolumn{2}{|c|}{ CFU-GM } & \multicolumn{2}{|c|}{ CFU-GEMM } & \multicolumn{2}{|c|}{ CFU-MEG } \\
\hline & Normal & HIV & Normal & HIV & Normal & HIV & Normal & HIV \\
\hline \multicolumn{9}{|l|}{ Day 5} \\
\hline Ep + GM-CSF & $490 \pm 39$ & $630 \pm 230$ & $244 \pm 10$ & $280 \pm 130$ & $63 \pm 6$ & $45 \pm 5$ & $22 \pm 1$ & $4 \pm 1 \dagger$ \\
\hline GM-CSF & $334 \pm 53$ & $530 \pm 340$ & $214 \pm 30$ & $235 \pm 75$ & $57 \pm 11$ & $50 \pm 10$ & $21 \pm 6$ & $8 \pm 1 \dagger$ \\
\hline \multicolumn{9}{|l|}{ Day 10} \\
\hline Ep-GM-CSF & $627 \pm 92$ & $697 \pm 53$ & $164 \pm 28$ & $217 \pm 12$ & $109 \pm 20$ & $110 \pm 59$ & $19 \pm 5$ & $12 \pm 4$ \\
\hline GM-CSF & $58 \pm 27$ & $220 \pm 190$ & $130 \pm 15$ & $200 \pm 90$ & $163 \pm 30$ & $185 \pm 75$ & $23 \pm 3$ & $28 \pm 3$ \\
\hline
\end{tabular}

* Colony count d 5 and 10 in cultures supplemented with Ep + GM-CSF or GM-CSF alone. Data were obtained from studying the responses of cell colonies from eight normal fetuses and five fetuses from HIV-seropositive females. CFU-MEG, colony-forming units-megakaryocyte.

$\dagger p<0.01$.

Table 4. Flow cytometric analysis of fetal liver hematopoietic cell phenotypes (\% of total \pm SEM)

\begin{tabular}{|c|c|c|c|}
\hline $\mathrm{MAb}$ & $\begin{array}{l}\text { HIV } \\
\text { fetuses }\end{array}$ & $\begin{array}{l}\text { Normal } \\
\text { controls }\end{array}$ & $p$ value \\
\hline $\mathrm{CD} 2$ & $1 \pm 0$ & $4 \pm 1$ & $<0.01$ \\
\hline CD19 & $2 \pm 1$ & $6 \pm 1$ & $<0.01$ \\
\hline $\mathrm{CD} 14$ & 0 & $3 \pm 1$ & $<0.02$ \\
\hline CD61 & $5 \pm 1$ & $10 \pm 2$ & $<0.06$ \\
\hline CD45 & $25 \pm 1$ & $32 \pm 4$ & NS \\
\hline CD34 & $6 \pm 2$ & $16 \pm 3$ & NS \\
\hline CD33 & $9 \pm 3$ & $21 \pm 7$ & NS \\
\hline Transferrin & $70 \pm 6$ & $69 \pm 8$ & NS \\
\hline CD36 & $65 \pm 12$ & $55 \pm 3$ & NS \\
\hline $\mathrm{CD} 4$ & $2 \pm 0$ & $2 \pm 0$ & NS \\
\hline
\end{tabular}

Table 5. Flow cytometric analysis of cells after $10 \mathrm{~d}$ in cultures*

\begin{tabular}{lcccccc}
\hline & CD45 & CD14 & Transferrin & CD36 & CD61 & CD33 \\
\hline NC Ep + & $13 \pm 2$ & $6 \pm 1$ & $84 \pm 6$ & $73 \pm 7$ & $6 \pm 1$ & $14 \pm 3$ \\
GM-CSF & & & & & & \\
HIV fetus Ep & $11 \pm 2$ & $11 \pm 3$ & $71 \pm 9$ & $68 \pm 4$ & $8 \pm 1$ & $26 \pm 4$ \\
$\quad$ + GM-CSF & & & & & & \\
NC GM-CSF & $34 \pm 7$ & $20 \pm 3$ & $29 \pm 6$ & $34 \pm 7$ & $24 \pm 6$ & $45 \pm 9$ \\
HIV fetus & $27 \pm 10$ & $27 \pm 6$ & $29 \pm 3$ & $35 \pm 4$ & $11 \pm 3$ & $55 \pm 10$ \\
GM-CSF & & & & & & \\
\hline
\end{tabular}

* Percentage of different phenotypes after $10 \mathrm{~d}$ in culture (mean \pm SEM). NC, normal control.

Table 6. Flow cytometric analysis of cells after $21 d$ in culture*

\begin{tabular}{|c|c|c|c|c|c|c|}
\hline & CD45 & CD14 & Transferrin & CD36 & CD61 & CD33 \\
\hline $\begin{array}{r}\mathrm{NCE} \\
\mathrm{GN}\end{array}$ & $38 \pm 11$ & $9 \pm 2 \dagger$ & $1 \pm 9$ & $49 \pm 10$ & $14 \pm 1$ & $4 \pm 1 \dagger$ \\
\hline $\begin{array}{l}\mathrm{HIV} f \\
+\mathrm{C}\end{array}$ & $30 \pm 5$ & $22 \pm 4 \dagger$ & $68 \pm 13$ & $62 \pm 6$ & $17 \pm 7$ & $14 \pm 3 \dagger$ \\
\hline $\mathrm{NCG}$ & & & & & & \\
\hline $\begin{array}{l}\text { HIV fetus } \\
\text { GM-CSF }\end{array}$ & & $39 \pm 7$ & & & $16 \pm 8$ & $16 \pm 4$ \\
\hline
\end{tabular}

* Percentage of different phenotypes (gated) after $21 \mathrm{~d}$ in culture. NC, normal control.

$\dagger p<0.02$.

$\ddagger p<0.01$.

to stimulation with Ep+GM-CSF or GM-CSF alone. There was an increased number of BFU-E on d 5 and 10 in HIV-associated cultures when compared to normal controls. Furthermore, phenotype analysis of cultured hematopoietic cells showed a significant increase in the number of CD14-positive cells on d 10, as well as a significant increase in the number of CD45-positive cells on $\mathrm{d} 21$.

Although there remains a possibility that the observed changes are the product of HIV-1 infection of hematopoietic precursor cells, the data obtained by PCR amplification of HIV-1 DNA sequences were negative for all liver tissues. Under conditions of
PCR that demonstrated the presence of 10-25 HIV-1 genome copies of control positive samples, no positive signal was detected. Therefore, other mechanisms are suspected to be responsible for the observed results.

These findings could be due to a rebound phenomenon. Because $T$ cells can inhibit the proliferation and differentiation of normal hematopoietic progenitor cells (by cell to cell interaction as well as by production of inhibitor factor), the separation of these progenitor cells from the endogenous inhibiting effect and the exposure to stimulating growth factor could produce the rebound effect.

The increase in CD14 phenotype in hematopoietic fetal liver cultures of abortuses from HIV-seropositive mothers could be similarly explained because most of the patients with AIDS have diminished numbers of circulating monocytes (6). All liver tissues were analyzed by PCR for HIV-1 DNA sequences and found to be negative. This fact supports our hypothesis that changes observed in the in vitro hematopoiesis of abortuses of HIVseropositive women might be a rebound effect caused by inhibitors produced by the maternal $\mathrm{T}$ cell subpopulations or a lack of inhibitors due to a significantly diminished number of early $\mathrm{T}$ cells observed in liver tissue of those abortuses. Infection of a small subpopulation of hematopoietic progenitor cells or macrophages could not be excluded in our study, but it is unlikely because infected progenitor cells lose their capacity to proliferate (11).

In conclusion, the present data demonstrate that fetuses of HIV-seropositive women exhibit a normal or even increased ability of their hematopoietic cells to proliferate and differentiate in tissue culture regardless of a direct or indirect HIV effect on the hematopoietic system of the host. Infection of a small subpopulation of hematopoietic progenitor cells below the level of detectability of the PCR, however, cannot be excluded. Whatever the mechanism causing bone marrow alterations in patients with AIDS, it appears not to have a nonreversible impact on the potential of fetal hematopoietic cells to differentiate.

Acknowledgments. The authors thank Agnes Geoghan for expert secretarial assistance. We also want to acknowledge cooperation from New York City Health and Hospitals Corporation and the Bronx Municipal Hospital Center with its excellent nursing staffs at Van Etten and Jacobi Hospitals.

\section{REFERENCES}

1. Barre-Sinoussi F, Chermann JC, Rey F, Nugeyre MT, Chamoret S, Gruest J Daugnet C, Axler-Blin C, Bezinet-Brun F, Rouzioux C, Rosenbaum W, Montagnier L 1983 Isolation of a T-lymphotropic retrovirus from a patient at risk for acquired immunodeficiency syndrome (AIDS). Science 220:868 871

2. Popovic M, Sarngadharan MG, Read E, Gallo RC 1984 Detection, isolation and continuous production of cytopathic retrovirus (HTLV-III) from patients with AIDS and pre-AIDS. Science 224:497-500

3. Fauci AS, Macher AM, Zongo DL, Lane HC, Rook AA, Masur H, Gelmann EP 1983 Acquired immunodeficiency syndrome; epidemiologic, clinical, immunologic and therapeutic considerations. Ann Intern Med 100:92-106

4. Schneider DR, Picker LJ 1985 Myelodysplasia in the acquired immune deficiency syndrome. Am J Clin Pathol 84:144-152 
5. Spivak JL, Selonick SE, Quinn TC 1983 Acquired immune deficiency syndrome and pancytopenia. JAMA 250:3084-3087

6. Treacy M, Lai L, Costello C, Clark A 1987 Peripheral blood and bone marrow abnormalities in patients with HIV related disease. $\mathrm{Br} \mathrm{J}$ Haematol 65:289294

7. Spikak JL, Bender BS, Quinn TC 1984 Hematologic abnormalities in the acquired immune deficiency syndrome. Am J Med 77:224-228

8. Ellaurie M, Burns ER, Rubinstein A 1990 Hematologic manifestations in pediatric HIV infection; severe anemia as a prognostic factor. Am J Pediatr Hematol Oncol 12:449-453

9. Geller SA, Muller R, Greenberg ML, Siegal FP 1985 Acquired immunodeficiency syndrome. Distinctive features of bone marrow biopsies. Arch Pathol Lab Med 109:138-141

10. Ganser A 1988 Abnormalities of hematopoiesis in acquired immunodeficiency syndrome. Blut 56:49-53

11. Carlo-Stella C, Ganser A, Hoelzer D 1987 Defective in vitro growth of the haematopoietic progenitor cells in the acquired immunodeficiency syndrome. J Clin Invest 80:286-293

12. Leiderman IZ, Greenberg ML, Adelsberg BR, Siegal FP 1987 A glycoprotein inhibitor of in vitro granulopoiesis associated with AIDS. Blood 70:12671272

13. Donahue RE, Johnson MM, Zon LI, Clark SG, Groopman JE 1987 Suppression of in vitro haematopoiesis following human immunodeficiency virus infection. Nature 326:200-203
14. Folks TM, Kessler SW, Orenstein JM, Justement JS, Jaffe ES, Fauci AS 1988 Infection and replication of HIV-1 in purified progenitor cells of normal human bone marrow. Science 242:919-921

15. Castella A, Croxon TS, Mildavan D, Witt DH, Zalusky R 1985 The bone marrow in AIDS. A histologic haematologic and microbiologic study. Am J Clin Pathol 84:425-432

16. Blanche S, Rouzioux C, Guihard Moscato ML 1989 Prospective study of infants born to women seropositive for human immunodeficiency virus type 1. N Engl J Med 320:1643-1648

17. European collaborative study 1991 Children born to women with HIV-1 infection: natural history and risk of transmission. Lancet 337:252-260

18. Lyman WD, Kress Y, Kure K, Rashbaum WK, Rubinstein A, Soeiro R 1990 Detection of human immunodeficiency virus in fetal central nervous system tissue. AIDS 4:917-920

19. Leiderman IZ, Greenberg ML, Adelsberg BR, Siegal FP 1989 Defective myelopoiesis in acquired immunodeficiency syndrome (AIDS). In: Gottlieb MS, Groopman JE (ed) Acquired Immunodeficiency Syndrome. Alan R Liss, New York, pp 281-289

20. Donahue RE, Johnson MM, Zon LI, Clark SC, Groopman JE 1987 Suppression of in vitro haematopoiesis following human immunodeficiency virus infection. Nature 326:200-203

21. Ganser A, Ottmann OG, Von Briesen H, Vokers B, Rubsamen TA, Waigmann H, Hoelzer D 1990 Changes in the haematopoietic progenitor cell compartment in the acquired immunodeficiency syndrome. Res Virol 141:185-193 